Territorios 37 / Bogotá, 2017, pp. 61-80

ISSN: 0123-8418

ISSNe: $2215-7484$

Ciudades y conflictos en América Latina: ayer, hoy, mañana (II)

\title{
Conflictos de apropiación de residuos reciclables e innovaciones socioinstitucionales en Lima*
}

Ownership Conflicts of Recyclable Waste and Socio institutional Innovations in Lima

Conflitos de apropriação de resíduos recicláveis e inovações sócioinstitucionais em Lima

Mélanie Rateau*

Recibido: 14 de agosto de 2016

Aceptado: 7 de abril de 2017

Doi: http://dx.doi.org/10.12804/revistas.urosario.edu.co/territorios/a.5086

Para citar este artículo:

Rateau, M. (2017). Conflictos de apropiación de residuos reciclables e innovaciones socio-institucionales en Lima. Territorios, (37), 61-80. Doi: http://dx.doi.org/10.12804/revistas.urosario.edu.co/territorios/a.5086

\begin{abstract}
* Este artículo forma parte del marco del proyecto de investigación ORVA2D (Organización de la valorización de los residuos en los paises en desarrollo) que el laboratorio Espace et Sociétés (UMR 6590) de la Universidad de Le Mans (Francia) viene llevando a cabo con apoyo financiero de la Agencia Francesa de Desarrollo (AFD, por sus siglas en francés). URL: eso-lemans.cnrs.fr/ $\mathrm{fr} /$ recherche/programmesen-cours/projet-afd.html. La corrección del español fue realizada por Heduen Estrella Burgos. Sociólogo de profesión y consultante para el proyecto ORVA2D en Bogotá.

* * Geógrafa de profesión, especialista sobre los servicios urbanos. Actualmente hace un doctorado en geografía de la Universidad $\Rightarrow$
\end{abstract}


Palabras clave

Innovación socioinstitucional, conflictos de apropiación, reciclaje inclusivo, recicladores informales, Lima.

Keywords

Socio-institutional innovation, appropriation conflicts, inclusive recycling, informal wastepickers,

Lima.

Palavras-chave

Inovação sócioinstitucional, conflitos de apropriação, reciclagem inclusiva, recicladores informais, Lima.

\section{territarias 37}

RESUMEN

Durante muchos años, las políticas públicas de manejo de los residuos desarrollaban acciones de represión hacia los actores del reciclaje informal. En Perú, desde la Ley del Reciclador del 2009, las políticas públicas se posicionan en favor de un reciclaje inclusivo, mediante la integración de los recicladores. Movilizando los conceptos de innovación socio-institucional y apropiación de residuos reciclables, el objetivo de este artículo es sustentar que las modalidades de implementación de la Ley conducen a la creación de modelos de gestión de residuos reciclables innovadores que permiten mitigar el conflicto del acceso a estos residuos entre recicladores formales, pero al mismo tiempo, este conflicto se desplaza desde el conjunto de los recicladores hacia generar una rivalidad entre formales e informales. Se destaca que, gracias a las innovaciones socio-institucionales, el nuevo interés institucional para el recojo selectivo no conduce a la creación de un conflicto de apropiación entre el servicio público de gestión y la lógica mercantil de reciclaje, como pudo haber sido.

\section{ABSTRACT}

For many years, the public policies of waste management developed repressive actions against the players in the informal recycling. In Peru, since the Law of Wastepicking of 2009, public policies are in favor of an inclusive recycling, through the integration of wastepickers. Using concepts of socio-institutional innovation and appropriation of recyclable waste, the aim of this work is to sustain that the modalities of implementation of the Law lead to the creation of innovative recyclable waste management models which enables to mitigate the conflict of access to these waste between formal wastepickers, but at the same time, this conflict moves from the set of wastepickers for generate a rivalry between formal and informal. It is emphasized that, thanks to socio-institutional innovations, the new institutional interest for selective collection does not lead to the creation of a conflict of ownership between the public management service and the mercantile recycling logic, as might have been the case been.

\section{RESUMO}

Durante muitos anos, as políticas públicas de gestão dos resíduos desenvolviam ações de repressão aos atores da reciclagem informal. No Peru, desde a Lei do Reciclador do 2009, as políticas públicas se posicionam em favor de uma reciclagem inclusiva, mediante a integração dos recicladores. Mobilizando os conceitos de inovação sócio-institucional e apropriação de resíduos recicláveis, o objetivo deste artigo é sustentar que as modalidades de implementação da Lei conduzem à criação de modelos de gestão de resíduos recicláveis inovadores que permitem mitigar o conflito do acesso a estes resíduos entre recicladores formais, mas ao mesmo tempo, este conflito deslocase desde o conjunto dos recicladores a gerar uma rivalidade entre formais e informais. Destaca-se que, graças às inovações sócio-institucionais, o novo interesse institucional para a recolhia seletiva não conduz à criação de um conflito de apropriação entre o serviço público de gestão e a lógica mercantil de reciclagem, como podia ter sido. 


\section{Introducción}

Durante el siglo XX, Lima, la capital peruana, ha experimentado un rápido y constante crecimiento urbano. Como en otras ciudades latinoamericanas, la gestión de residuos se ha convertido en un problema importante motivado por el rápido proceso de urbanización y el creciente consumo. Sin embargo, la mayoría de los residuos es recuperable y reciclable, constituyendo un significativo potencial económico. En este contexto, el reciclaje es una fuente de ingresos para miles de familias en la capital peruana.

En la literatura, la definición de desecho oscila entre dos visiones. En la primera, el desecho es un objeto abandonado por su dueño, quien lo considera sin valor (Cointreau-Levine, 1982). El estado de ser desecho "deviene final, una externalidad urbana, que se traduce en objeto abandonado" (Barles, 2005 , p. 246). En otra visión, se acepta que cuando el objeto esta desechado en la vía pública, puede estar apropiado y llegar a ser un bien privado de nuevo (Wilson, Velis \& Cheeseman, 2006). Esta indeterminación de la propiedad del desecho suscita formas de competencia (Cavé, 2013) en el seno de los actores del reciclaje informal (Moreno-Sainz, 2007; Scheinberg, Spies, Simpson \& Mol, 2011) pero también con los otros actores del manejo de los residuos (UN-HABITAT, 2010).

Durante muchos años, las políticas públicas de manejo de los residuos sólidos seguían una lógica higienista de recolección-evacuación (Barles, 2005). El reciclaje no hacía parte de sus prioridades y, para tratar de limitar los riesgos relacionados con los residuos, desarrollaban políticas de represión en contra de los actores del reciclaje informal. Estas políticas y las formas de competencia constituyen, así, una fuente de conflictos potenciales ( $\mathrm{Fu}-$ redy, 1992; Wilson et al., 2006; Coffey \& Coad, 2010; GTZ, 2010) para acceder al recurso "desecho" o, más precisamente, al recurso "residuo reciclable".

Frente a la reciente preocupación medioambiental internacional, asistimos a un cambio de paradigma (Cavé, 2013). En este marco, Perú es el primer país en tener una ley que regula la actividad de los recicladores $^{1}$, la Ley N. ${ }^{\circ} 29419$ promulgada el 7 de octubre del 2009, aunque otros Estados ya han aplicado políticas en este sentido, como por ejemplo en Buenos Aires, Argentina (Moreno-Sainz, 2007). Las municipalidades distritales, responsables del manejo de los residuos sólidos en sus territorios de jurisdicción, van así a experimentar modalidades de implementación de la ley conduciendo los modelos de gestión hacia innovaciones socio-institucionales.

La innovación es un concepto ambiguo (Paulré, 2017), porque indica tanto la actividad innovadora como su resultado. Este trabajo se basa sobre la definición propuesta por Paulré (2017):

Innovar es crear e introducir, deliberada y específicamente, en una situación o un sistema existente, una nueva manera de hacer o un nuevo producto que es de interés para
$\Longleftarrow$

Paris-Est (Francia), en el laboratorio de investigación Techniques Territoireset Sociétés (UMR 8134) sobre la electricidad en África. Antes, investigó sobre el manejo y la valorización de residuos sólidos, especificamente en América Latina (Bogotáy Lima). Correo electrónico: melanie.rateau@hotmail. com. ORCID: http://orcid. org/0000-0002-6191-9729

${ }^{1}$ En este texto, "recicladores" está entendido como las personas que recogen los residuos reciclablespara luego venderlos. territarios 37

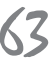


los usuarios o beneficiarios, es decir, que se reconoce como más eficaz o más atractiva que la oferta o las modalidades actuales de la satisfacción (p. 3).

Ahora, cuando se trata de una innovación institucional, se refiera a: "el proceso de acción colectiva por medio del cual un nuevo arreglo institucional está introducido en un sistema social específico" (Delpeuch, 2017, p. 2). En este artículo, se trabaja la innovación socio-institucional, es decir, añadimos a las definiciones anteriores, la de Bernal (2015) que propone el concepto de innovación social, la cual está entendida como el desarrollo de nuevos procesos, practicas, usos, métodos y aplicaciones en los cuales se implementa o se fortalece la participación de la comunidad o de los usuarios y que permiten o tienen el potencial de disminuir los costos, mejorar las tazas de cobertura o aumentar el nivel de calidad, pertinencia y eficacia de un proyecto (Bernal, 2015).

Dado el marco teórico, este trabajo evalúa en qué medida los distintos modelos de formalización de los recicladores consiguen reducir los conflictos de apropiación de residuos reciclables entre los actores del manejo de residuos sólidos. Para lo cual, en la primera parte del artículo, se presenta el contexto estructural de tensiones entre estos actores antes de la publicación de la Ley del Reciclador. En la segunda parte, se analizarán las modalidades de integración de los actores del reciclaje en función del grado de integración y de control territarias 37 64 presentará los resultados de estos modelos en términos de estabilización del conflicto de apropiación.

Para ello se realizó una revisión detallada de la literatura para así entender las evoluciones acerca de las políticas públicas de valorización de residuos reciclables y de integración o represión de actores informales del sector. En esta etapa se evidenció la fragmentación territorial de la aplicación de la Ley del Reciclador a la escala distrital. De los cincuenta distritos de Lima, se eligió tres con características diferentes en términos de cantidad y tipo de residuos generados, capacidad financiera y técnica de las municipalidades y el nivel socioeconómico de la población. Para la segunda parte del trabajo empírico, se recuperaron, sistematizaron y analizaron datos e informaciones que brindaron las tres municipalidades distritales de Lima estudiadas (Comas, Santiago de Surco y Villa María del Triunfo) concernientes a su gestión de residuos y modelos de implementación de la Ley. Entrevistas semiestructuradas con sus funcionarios, complementaron estos datos para entender las estrategias y expectativas oficiales. La misma metodología se trabajó para los actores informales y formalizados. Por otro lado se hicieron observaciones participantes, lo que permitió entender las consecuencias efectivas de los modelos en el trabajo de estos actores. Las ONG involucradas en el proceso de formalización de los recicladores de estos tres distritos estuvieron también entrevistadas y facilitaron informaciones, sobre todo la ONG Alternativa para el caso de Comas y 
la ONG Ciudad Saludable para el de Villa María del Triunfo. En la última parte de este artículo se presentan extractos de entrevistas con recicladores de otros distritos diferentes de este estudio pero que fortalecen los argumentos propuestos.

\section{Contexto estructural de tensiones con los recicladores antes de la Ley del Reciclador}

\subsection{Modelo higienista de evacuación de los residuos y reciclaje informal}

La metrópoli de Lima está dividida entre dos municipalidades provinciales (Lima y Callao) y cincuenta municipalidades distritales. Las primeras son responsables de la planificación del manejo de residuos municipales y de su eliminación, en tanto las segundas se encargan de la prestación de servicios de barrido de calle, recolección y transporte de residuos a las instalaciones de eliminación (Ley General de Residuos Sólidos, 2000). Estas tareas pueden ser realizadas directamente por los servicios municipales o confiadas a un prestador de servicio privado. La gestión de los residuos está motivado por un fin de servicio público higienista de evacuación de desechos fuera de la ciudad (Barles, 2005 ). En paralelo de este sistema higienista formal (ver figura 1), se desarrollan estrategias de recuperación de los residuos reciclables por parte de actores informales conscientes de sus potenciales económicos (Furedy, 1992).
El sector informal de la gestión de residuos se refiere a las personas naturales (individuos y familias) y pequeñas empresas privadas que participan en la gestión de residuos, sin embargo no tienen un vínculo contractual, no son apoyadas, reconocidas formalmente a cargo de los servicios de gestión de residuos por las autoridades competentes (Gunsilius, Chaturvedi \& Scheinberg, 2011; Gupta, 2012). Estas personas o empresas recogen o compran los residuos reciclables para venderlos, a veces después de tratamiento previo y así obtener un beneficio económico. Las dos características de este sector son el considerar los residuos como recurso según una lógica mercantil (Cavé, 2013) y, al mismo tiempo, sufrir de descredito social (Nas \& Jaffe, 2004). Asimismo, el sector informal está presente en casi todas las etapas de la cadena de valorización de los residuos reciclables: 1) el recojo de residuos reciclables, 2) la comercialización de proximidad, 3 ) comercialización al por mayor a empresas especializadas por tipo de material. No está presente en la última etapa (4), la de transformación o exportación (Gerold, 2009; Durand, 2010).

Las prácticas laborales de este sector informal son muy variadas y dependen de su especialización, ya sea de recuperación o de compra/venta. En Perú, en el lenguaje común, los actores del reciclaje informal se caracterizan según el material que reciclan. Entre los nombres más comunes se encuentran los "recicladores" que recogen, clasifican, acumulan y venden por separado el papel, cartón, plásticos, latas 
Figura 1. Modelo higienista del manejo de los residuos confrontado al sector informal antes de la Ley del Reciclador

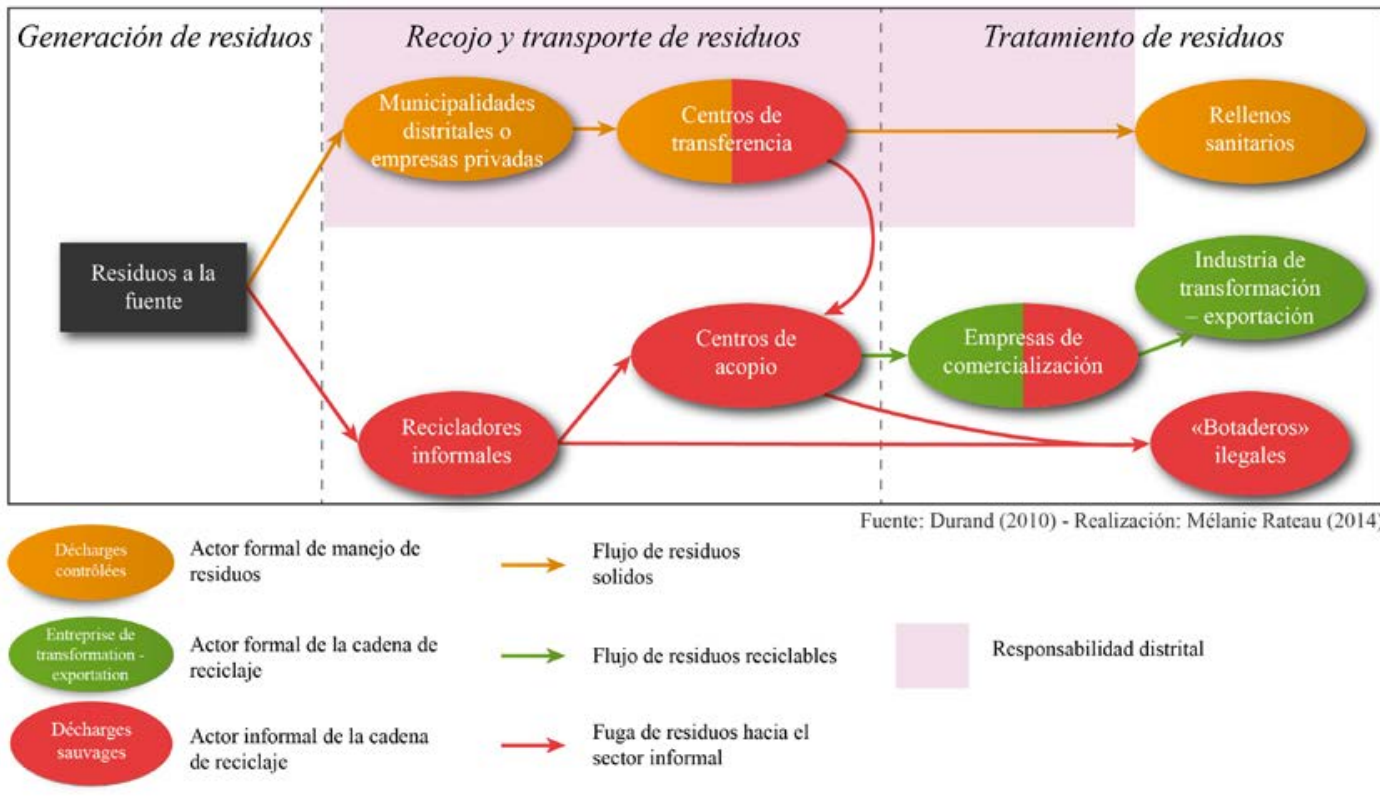

Fuente: Elaboración propia con datos de Durand (2010).

y botellas de vidrio. Desvían, así, los residuos reciclables más lucrativos (Bertolini, Foully \& Morvan, 1999). Es un trabajo mayormente individual o familiar de constante competencia. Luego, en la etapa de comercialización de proximidad, están los "centros de acopio" que compran al peso estos residuos.

En la primera etapa de la cadena del reciclaje, al lado de estos recicladores, se encuentran los "chatarreros" que compran y venden los metales, los "campaneros" que llevan el servicio de recojo de residuos tersitarias 37 a los hogares, los "chancheros" recuperan residuos orgánicos para alimentar a animales, los "cachineros" que compran y venden electrodomésticos y muebles en desuso. Existen otros actores que recogen los residuos reciclables para luego venderlos, aunque no sea su actividad laboral, como por ejemplo los empleados del camión de recojo de desechos urbanos y generadores de residuos.

\subsection{Represión contra las prácticas informales}

El reciclaje permite vivir en la metrópoli de Lima-Callao a más de 45000 recicladores (ONG Ciudad Saludable, 2010), sin 
embargo esta actividad fue excluida durante mucho tiempo de la gestión pública. Las municipalidades, tratando de limitar los riesgos ambientales y sanitarios del mal manejo de los residuos, adoptan posiciones distintas que se pueden ordenar en cuatro categorías: ignorancia, represión, colusión e integración (Medina, 2005). Esta última posición fue muy marginal en Lima antes de la Ley, principalmente dependió de proyectos de algunas ONG (Madueño, 2012). Las municipalidades de Lima eligieron en su mayoría reprimir a los recicladores, quitándoles el triciclo o denunciándolos a la policía, justificándose con una legislación nacional tan estricta y exigente que los recicladores no podían respetarla. Para estar legalizados, tenían que constituirse en empresa prestadora de servicio de residuos sólidos. Sin embargo, la mayoridad de los recicladores no tiene los recursos jurídicos, financieros y técnicos para crear empresas capaces de competir con otras empresas prestadoras de servicio. Estos efectos de exclusión proceden también de la modernización (Florin, 2010) de la gestión municipal de los residuos cuando el sector informal está considerado como arcaico (Wilson et al., 2006): "el proceso de modernización crea a menudo una competencia entre autoridades formales y empresas informales alrededor de materiales" (GIZ, 2010, p. 8).

A pesar de este contexto desfavorable, la forma de considerar a los recicladores evoluciona poco a poco. Con las preocupaciones ambientales ascendentes, un consenso a favor de la integración de los recicladores se manifestó en los años 2000 para implementar la recolección selectiva sin perjudicar a una economía local y eficaz a pesar de su informalidad (Scheinberg \& Anschütz, 2006; Wilson et al., 2006; Bertolini \& Brakez, 2008; Gupta, 2012). Los expertos empezaron a reconocer los beneficios económicos, sociales y medioambientales del sector informal de recuperación de residuos y reciclaje (Wilson, Araba, Chinwah \& Cheeseman, 2009). Regular y formalizar este sector endógeno prevalece sobre la creación de sistema de recojo selectivo exógeno (Wilson et al., 2006).

\section{Modalidades de implementación de la Ley del Reciclador: hacia innovaciones socio-institucionales}

\subsection{La Ley del Reciclador y la recolección selectiva}

La Ley del Reciclador N. ${ }^{\circ} 29419$ busca fomentar la formalización de los recicladores y el establecimiento del recojo selectivo mediante la integración de estos actores informales. Para ello, las municipalidades distritales tienen dos misiones: formalizar a los recicladores e implementar el Programa de segregación a la fuente y de recolección selectiva (PSF-RS). Para integrar estos actores informales en su sistema local de gestión de residuos sólidos, definen un proceso administrativo (ver figura 2) por ordenanza municipal y que varía de un distrito a otro. Entonces, las municipalidades ponen en marcha el proceso territarias 37

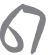


Figura 2. El proceso de formalización e integración de los recicladores

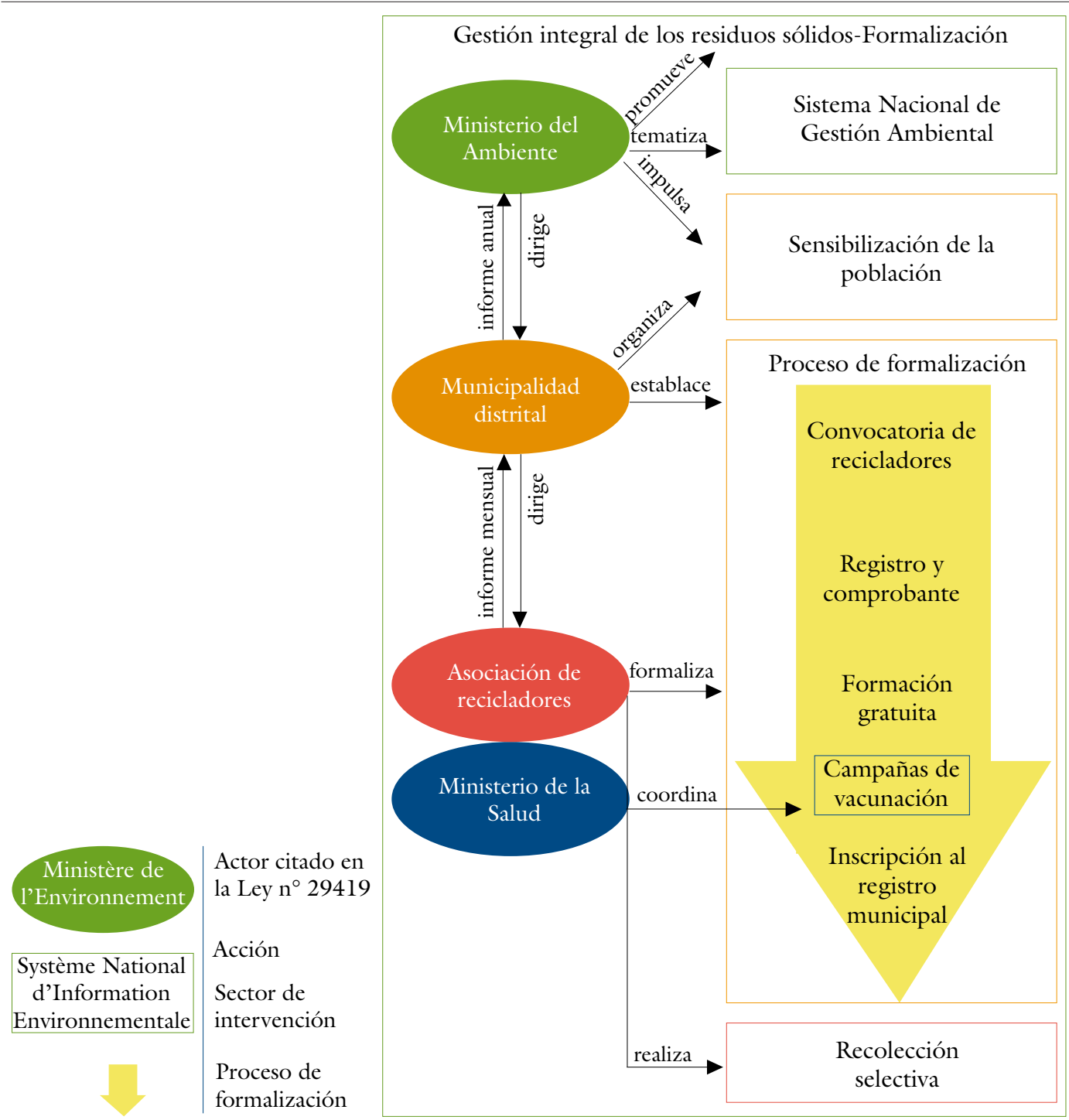

Fuente: Elaboración propia con datos de la Ley del Reciclador N. ${ }^{\circ} 29419$. 
administrativo. Este proceso comienza con una convocatoria a los recicladores. Se registran y obtienen un comprobante que les da acceso a la formación obligatoria y a una campaña de vacunación. Por último, los recicladores que siguieron este proceso tienen que registrarse en el registro municipal bajo forma asociativa, que les da derecho a colectar los residuos reciclables.

En cuanto al proceso de implementación de los PSF-RS, sigue tres pasos (ver figura 3 ). En primer lugar, se define las áreas de recolección selectiva. Luego, los promotores ambientales municipales van a las zonas a identificar los hogares que deseen participar en el PSF-RS. A estos se les entrega una bolsa de color para separar los residuos reciclables. Finalmente, cada reciclador va a su zona de acuerdo a los horarios definidos por el distrito, uniformado para diferenciarse de un reciclador informal. Recuperará las bolsas de color llenas de residuos reciclables y dará nuevas a cambio. Una vez la recolección realizada con un triciclo (eventualmente motorizado), el reciclador formal clasifica los materiales recogidos para después venderlos a centros de acopio. Es importante precisar que las municipalidades no remuneran a los recicladores a pesar de que estén integrados en PSF-RS. Les facilitan una zona, sus primeros uniformes y, a veces, las bolsas de color, pero la venta de los residuos es su fuente de ingresos.

Después de la publicación oficial de la vigente Ley del Reciclador, el Estado peruano lanzó una campaña de incentivos, con el objetivo de motivar a las

Figura 3. Etapas esenciales para la implementación del recojo selectivo

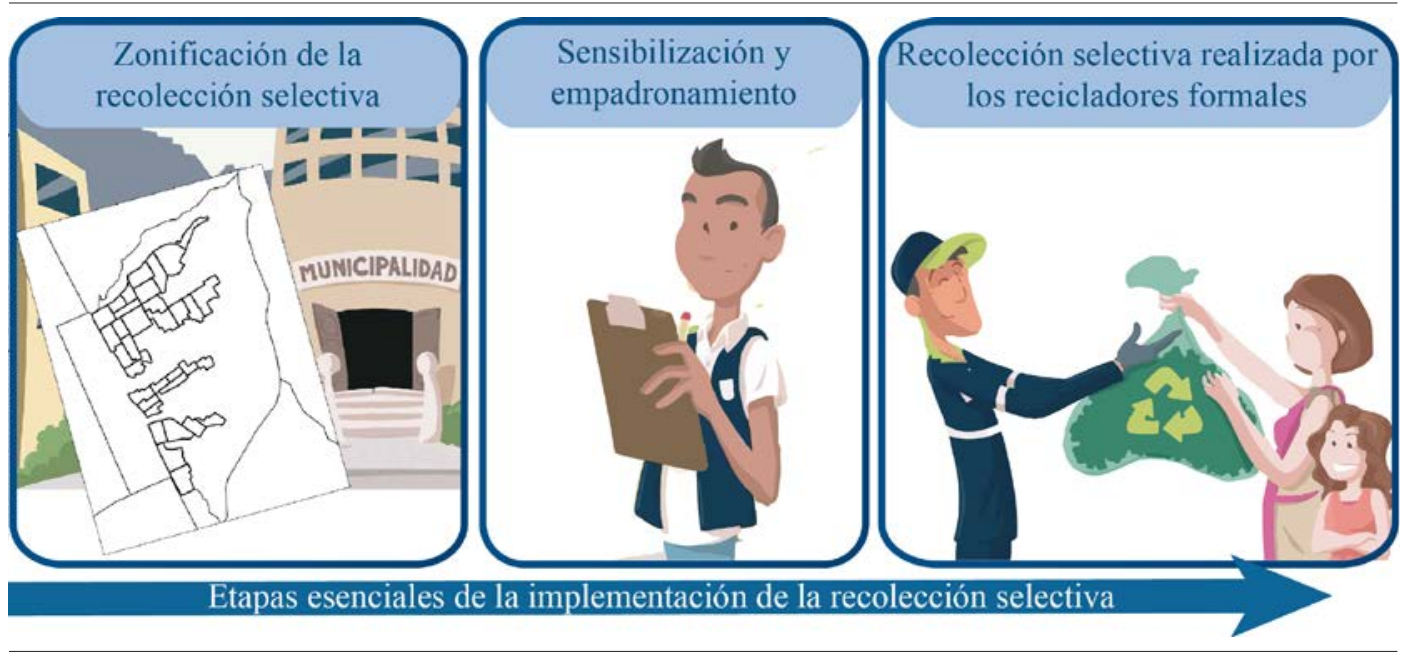

Fuente: ONG Alternativa \& Rateau (2014). 
municipalidades a integrar los recicladores para implementar la recolección selectiva. El Ministerio del Ambiente fija anualmente objetivos cifrados para que las municipalidades que trabajan su PSF-RS con recicladores, reciban incentivos financieros. Por ejemplo, en julio de 2014, la meta era tener un $25 \%$ de los hogares inscritos en el programa.

\subsection{Diversidad de implementación de los PSF-RS: ejemplos de tres distritos}

El distrito de Santiago de Surco, distrito acomodado en el centro económico de Lima, es un precursor en la implementación del recojo selectivo en la capital peruana, desde 2001. Su empresa municipal de manejo de los residuos reciclables actualmente es rentable y está invirtiendo en una nueva faja de clasificación automatizada para incrementar su productividad. Desde la Ley del 2009 y la obligación de integrar recicladores para obtener el incentivo del Ministerio del Ambiente, la política del distrito se orienta en favor de su integración. Está previsto una repartición de la recolección selectiva por tipo de edificios: los condominios donde falta espacio para guardar los residuos reciclables por una semana, serán de responsabilidad de los recicladores que se formalicen, por ende la municipalidad será encargada de las viviendas independientes. En este distrito, el punto de interés es la futura complementariedad entre la empresa municipal y los recicladores formales.
El distrito de Comas, distrito popular ubicado en Lima Norte, ha elegido integrar no solamente a los recicladores (con apoyo de la ONG Alternativa), sino también a los centros de acopio. Estos centros formalizados aplican tarifas preferenciales para los recicladores formales lo cual es una motivación para los informales de dar el paso a la formalización y así vender sus materiales a un precio mayor. Además de este binomio (reciclador-centro de acopio) la municipalidad prevé la implementación de un centro de transferencia que cumpla también la función de empresa comercializadora de residuos reciclables. Esta empresa permitirá transferir los desechos de camiones compactadores de recojo hacia camiones de mayor capacidad de tonelaje que transportarán estos desechos hasta los rellenos sanitarios. Además, comprará el reciclaje de los centros de acopio formalizados evitando así la desviación hacia el sector informal.

Villa María del Triunfo, distrito popular en Lima Sur, implementó su PSF-RS en 2012, un año después de Comas, pero se enfrenta a una serie de dificultades. El número de recicladores integrados al programa y la cantidad de toneladas recicladas son mínimas. Son trece los recicladores formalizados pero solo ocho hacen el recojo selectivo que alcanza cuatro toneladas mensuales, mientras que en Comas son diecisiete recicladores para un recojo de veinticinco toneladas al mes y treinta recicladores en proceso de formalización en 2014. Surco, con su empresa municipal, alcanza más de doscientas veinte toneladas 
cada mes. Sin embargo, en Villa María del Triunfo hay algunas innovaciones interesantes a resaltar. Por ejemplo, parte del material de sensibilización, uniformes de los recicladores, herramientas e incluso el proyecto de la ONG Ciudad Saludable, son financiados por la Unión de los cementeros (UNACEM) ubicada en el distrito. Igualmente, para incentivar a los hogares, $\mathrm{co}^{-}$ mercios e instituciones a participar en la recolección selectiva, la municipalidad les entrega a cambio de su bolsa de reciclaje, un bono de descuento de $20 \%$ sobre los arbitrios.

\section{3 ¿Modelos innovadores para implantar la recolección selectiva?}

La municipalidad de Santiago de Surco inicio su PSF-RS con una primera faja de clasificación mecanizada. Frente al aumento considerable de residuos reciclables recogidos, la empresa municipal opta ahora por la construcción de una nueva faja automatizada gracias a nuevas tecnologías. Sin duda, recurrir a las nuevas tecnologías hace del modelo de este distrito un modelo innovador. Pero, desde algunos años el concepto de innovación evoluciona de una noción puramente tecnológica hacia una definición más amplia que puede integrar dimensiones institucionales y sociales.

El mejor ejemplo de innovación socioinstitucional es la que prueban los distritos en la implementación de la recolección selectiva gracias a la integración y formalización de los actores informales. Esta innovación efectivamente mejora el manejo de los residuos sólidos, pero también disminuye sus costos, gracias a los gastos evitados mediante la desviación de una parte de las toneladas de residuos hacia el recojo selectivo. De hecho, las municipalidades pagan el servicio de gestión de los desechos por toneladas, mientras que no pagan a los recicladores por el servicio aportado.

En ese sentido, el distrito de Comas es innovador. Por un lado tiene como objetivo desarrollar el capital económico del sistema formal de valorización de los residuos. También el capital social, ofreciendo empleos formales a recicladores, acopiadores y promotores ambientales, sin dejar de lado el capital ambiental, institucional y cultural. La innovación institucional del PSF-RS de Comas reside en la institucionalización de la complementariedad entre la municipalidad, recicladores y centros de acopio. Esta complementariedad es reconocida institucionalmente por la ordenanza de aprobación del PSF-RS.

El modelo de Villa María del Triunfo es menos innovador en términos de integración social. Los únicos actores integrados son los propuestos en la Ley del Reciclador de 2009. La particularidad de su modelo reside en la territorialización a escala local de innovación socio-institucional. Su PSF-RS se trabaja con la ONG Ciudad Saludable, gracias al financiamiento local de la UNACEM que, a cambio, recibe certificaciones socio-ambientales por parte de la ONG que atestan de su compromiso socio-ambiental. En cambio, Comas desarrolla su PSF-RS en colaboración con la ONG Alternativa, particularmente dentro territarias 37

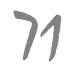


del proyecto "Recicla para la vida" que está financiado por fundos internacionales. Este apoyo de las ONG completa el incentivo financiero del Ministerio del Ambiente.

\section{4 ¿Tres distritos, tres modelos que coinciden?}

Los modelos actuales de manejo de los residuos reciclables de las municipalidades de Santiago de Surco, Comas y de Villa María del Triunfo no son estáticos. Estas municipalidades tienen proyectos en realización: una se orienta en favor de la integración de los recicladores, la otra construyendo un centro de transferencia-empresa comercializadora y la última, deseando integrar a los acopiadores.

La municipalidad de Santiago de Surco basa su modelo actual de manejo de residuos reciclable solamente sobre su empresa municipal. Realiza el recojo selectivo, clasificación y comercialización destinado directamente a la industria o exportación. En el futuro va a integrar una asociación de recicladores, orientándose hacia un modelo eficaz en términos de control de la cadena del reciclaje, desde el recojo hasta la penúltima etapa de la cadena, favoreciendo también la integración de actores informales (ver figura 4).

El modelo desarrollado por Comas apuntó hacia la integración de los actores informales, antes que priorizar lógicas de rentabilidad. El resultado es que actualmente recicladores y centros de acopio están formalizados e integrados. Las toneladas recuperadas por los recicladores formales son mínimas en comparación a Surco. Sin embargo este modelo tiene la ventaja de integrar dos etapas de la cadena de valorización tradicionalmente informales, pero su aplicación tiene que ser mejorada para ser eficaz. Nuevos recicladores van a ser integrados al futuro modelo, este contaría con un centro de transferencia y empresa de comercialización, la cual comprará el reciclaje a los centros de acopio ya formales. Así, el futuro modelo de Comas se orienta hacia la eficacidad, control de la cadena de reciclaje e integración.

En el modelo de Villa María del Triunfo, los recicladores, una vez la recolección selectiva efectuada, están libres de vender sus residuos reciclables al centro de comercialización de su elección. El modelo actual es, entonces, poco eficaz en términos de control de la cadena del reciclaje, pero tiene el interés de integrar a los centros de acopio. El proyecto municipal va más allá de la sola integración a los recicladores, deseando efectivamente integrar también a centros de acopio. El futuro modelo alcanzaría así al modelo actual de Comas, en favor de la integración global de los actores informales.

La comparación del grado de integración de los actores informales y del nivel de control de la cadena del reciclaje en estos tres modelos (ver figura 4) permite destacar las evoluciones hacia un único modelo centrado sobre innovaciones socioinstitucionales.

\section{territarias 37}


Figura 4. Actores integrados a la gestión de los residuos reciclables en Santiago de Surco, Comas y Villa María del Triunfo

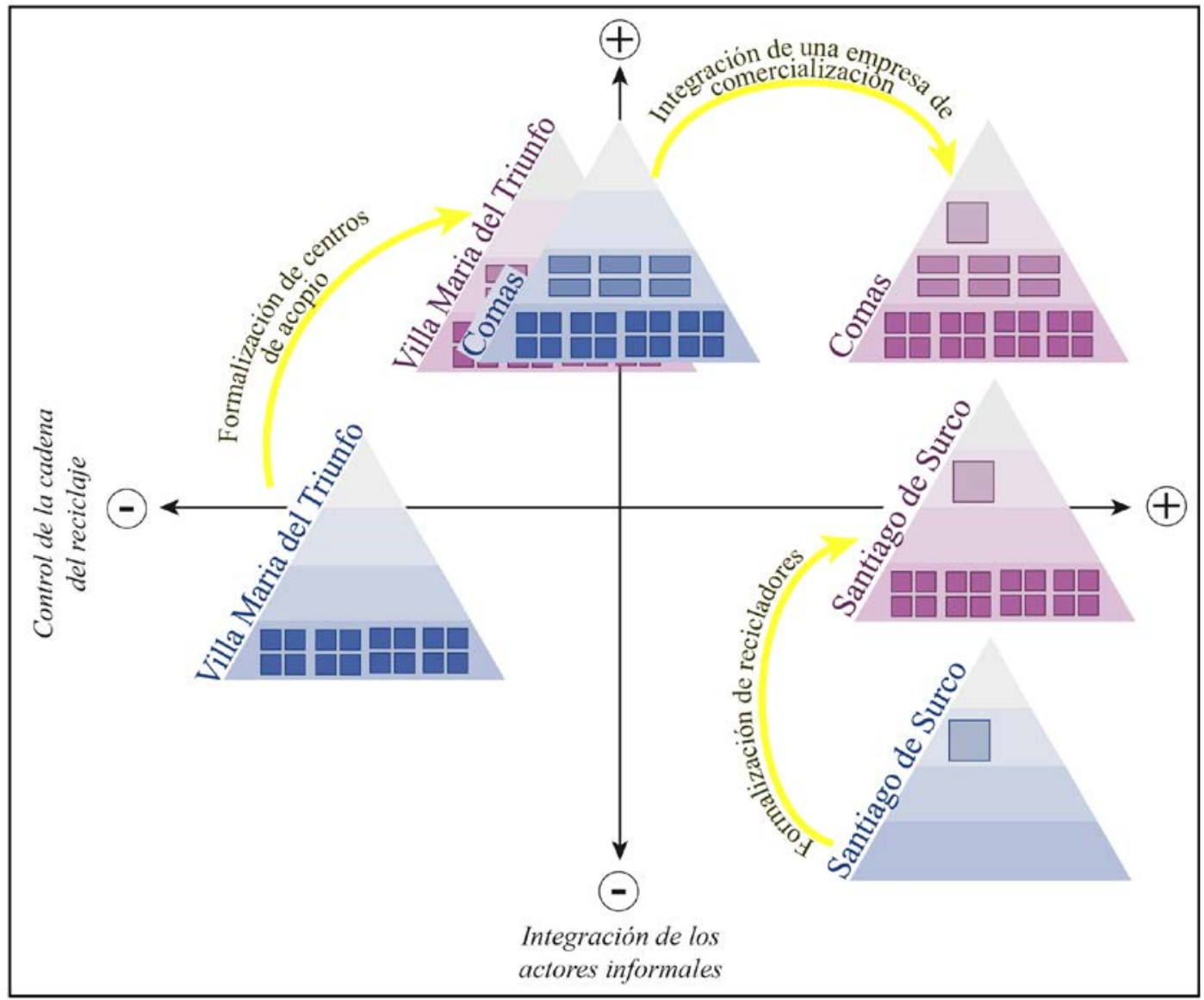

Gestión municipal de residuos reciclables:

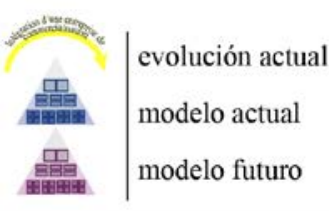

Etapa de la cadena del reciclaje: :

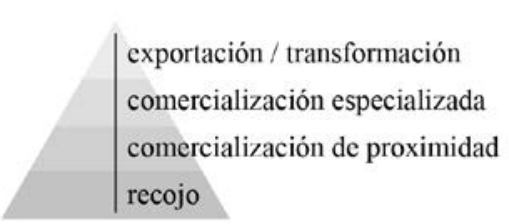

Actores integrados a la gestión municipal:

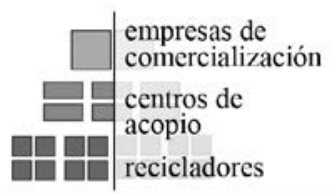

Fuente: Elaboración propia con datos de las municipalidades de Comas, Santiago de Surco y Villa María del Triunfo (2015). 


\section{Resultados de la integración a matizar}

\subsection{En camino hacia mejores condición socio-económica de los recicladores}

La Ley del Reciclador está social y ambientalmente: "orientada a la protección, capacitación y promoción del desarrollo social y laboral, promoviendo su formalización, asociación y contribuyendo a la mejora en el manejo ecológicamente eficiente de los residuos sólidos en el país" (Ley N. 29419 del 2009). Este interés social es evidente en las entrevistas. Cuando los recicladores evocan las razones de su formalización, la primera motivación es social. Históricamente marginados, han visto la posibilidad de ganarse el respeto de los vecinos, el apoyo de las autoridades locales y transformar su actividad precaria en un trabajo reconocido y ordenado. De hecho, una recicladora dice:

Yo me formalicé porque la municipalidad nos dio una oportunidad para que los vecinos nos reconozcan como personas que somos trabajadores y para que no tengamos ese miedo, de que cualquier día van a hacer una batida y nos van a quitar el triciclo, todo eso (Entrevista a Estefita Paredes, 2014).

Gracias al PSF-RS, las condiciones de trabajo de los recicladores formalizados e integrados son menos difíciles: dejaron de

\section{territarias 37} 74 los hogares inscritos en este programa. La salud de los recicladores y sus familias ha mejorado, ya no están expuestos a riesgos sanitarios tales como residuos peligrosos. Por el contrario, ahora acceden obligatoriamente al sistema de salud público (seguro social y campaña de vacunación). Respecto a los ingresos, las ONG explican que estos no suben de forma sistemática mediante su formalización, pero devienen regulares. De hecho, los recicladores ya no tienen que competir para acceder a los residuos reciclables. Tienen sus zonas de recolección selectiva en las cuales los residuos reciclables le corresponden. Explican que gracias a esta nueva estabilidad, algunos recicladores podrán financiar los estudios de sus hijos, rompiendo así con los esquemas de reproducción de la pobreza. Lo confirma un reciclador:

Mi meta era solamente que mis hijas se formen por eso yo también me formalicé, porque si no tengo trabajo no tenía cómo ayudar, ni siquiera para el pasaje. Las dos estaban en la universidad y dije ¡si yo dejo el campaneo y no entro como reciclador de qué vivo?, ‘a mis hijos de dónde llevo para su pasaje? En el futuro, ya mis hijas, la mayor ya se formó, falta solamente sacar su tesis, su título. La menor está en camino, en diez años ya van a ser profesionales, de repente van a decir, ya papá no trabajes, en la casa ayuda en lo que sea, limpia la casa, haz el aseo del perro, yo qué sé. En el futuro como mis hijas... esa era mi meta, que mis hijas se formen (Entrevista a Eugenio Huanca, 2014). 
Muchos testimonios han demostrado que el funcionamiento en asociación permite crear solidaridad entre los socios y un enriquecimiento de la vida social, como lo cuenta una recicladora:

Antes, por ejemplo, yo no conversaba, era muda, paraba encerrada en mi cuarto, no salía para nada. Ahora participo en muchas cosas $[\ldots]$ Apenas saludaba antes, ahora converso (Entrevista a Vanessa Dávalos, 2014).

El reciclaje informal en la calle es una actividad muy competitiva. Es una actividad de sobrevivencia (Gaudio Soares, 2004) que impone a los recicladores una lógica individual fuerte para acceder al recurso "residuo reciclable". En el proceso de formalización los recicladores tienen que organizarse en asociación para que las municipalidades les autoricen trabajar. A la diferencia de otros ejemplos, como en Argentina (Moreno-Sainz, 2007), esta lógica colectiva es nueva para muchos recicladores limeños. Pasan progresivamente de una lógica individual hacia una forma asociativa que les permite encontrar soluciones institucionales a los conflictos gracias a una mayor representatividad frente a la municipalidad. Este proceso lleva también a dinámicas de emprendimiento empresarial. Por ejemplo, algunos recicladores participan en proyectos de creación de micro-empresas de centro de acopio.

CONFLICTOS DE APROPIACIÓN DE RESIDUOS RECICLABLES E INNOVACIONES SOCIO-INSTITUCIONALES EN LIMA

\subsection{Acentuación de la marginalización de los informales}

Desde sus posibles integraciones en el PSF-RS, los recicladores ya no están universalmente aceptados o marginalizados. Los recicladores formalizados, usando el uniforme con el nombre de la municipalidad son considerados por los vecinos como "empleados" de la municipalidad. En cambio, los informales son víctimas de una acentuación de la marginalización, incluso por parte de los recicladores recién formalizados que piden sanciones contra ellos. La fuerte presencia de recicladores informales en las calles conduce a situaciones de competencia entre formales e informales (ver figura 5), como lo relatan dos recicladoras:

Cuántas veces ya le hemos dicho [a la municipalidad] que queremos que hagan batidas para que no haya informales, los informales no nos dejan trabajar a nosotros. Se van por mi zona, recogen, tocan la puerta y se hacen pasar por mí (Entrevista a María Elena Barrueto, 2014).

Nos falta bastante apoyo de la municipalidad, sobre todo porque uno, nosotros somos pocos los formales y sí siguen aumentando los informales [...] (Entrevista a Estefita Paredes, 2014).

Esta represión demandada por los formales en contra de los informales se aplica en el distrito de Comas. El Gerente de 


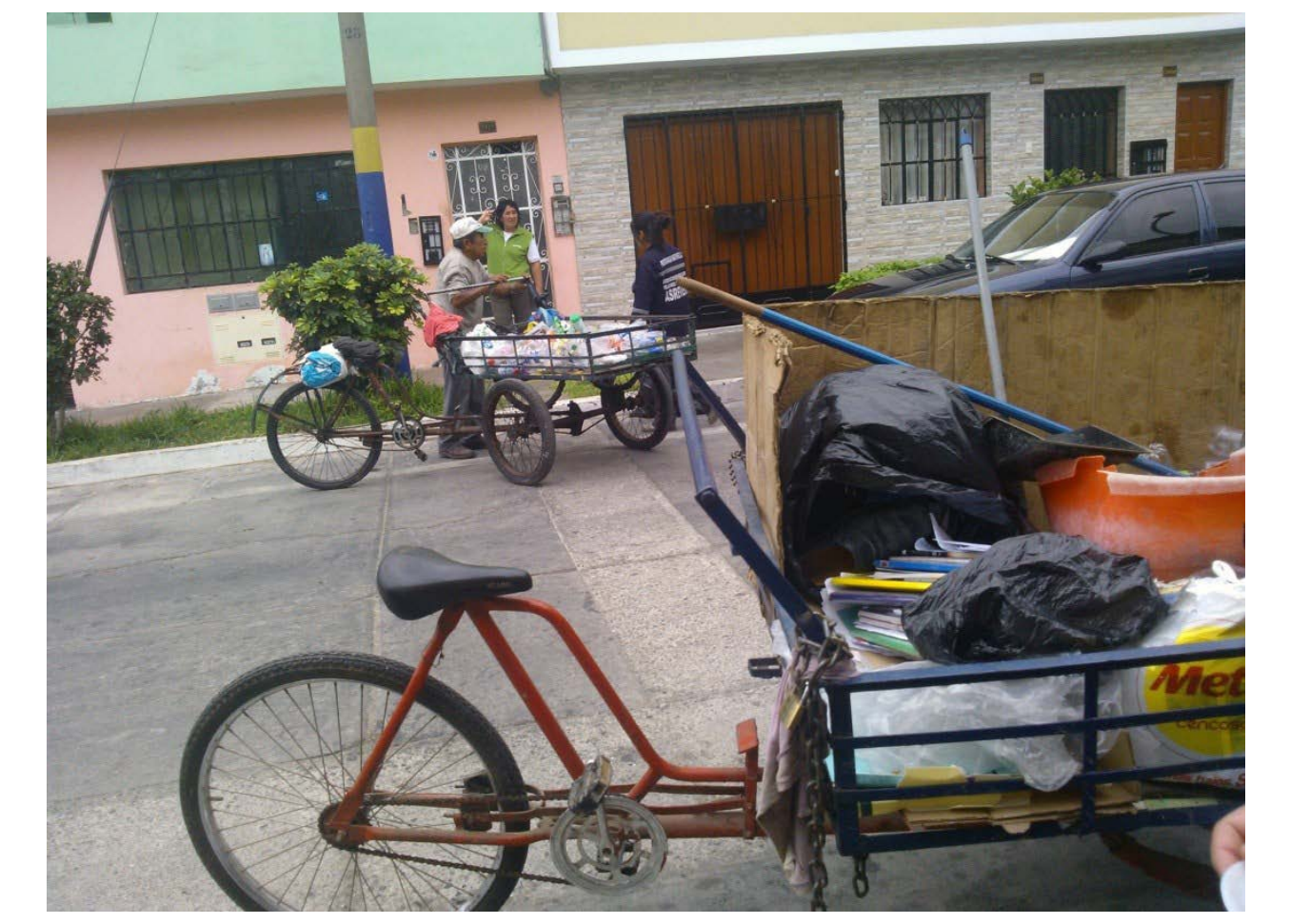

Fuente: Elaboración propia (2014).

Limpieza Publica explica que la municipalidad sigue dos pasos con los informales. Primero, intenta motivarlos con una campaña de información sobre el PSF-RS y las ventajas de trabajar formalizados. De lo contrario, la municipalidad pasa a la segunda etapa. Les quita el triciclo y deben pagar una multa para recuperarlo. Trabajar sin triciclo significa la disminución de ingresos y condiciones de trabajo más difíciles. De hecho, el conflicto se desplaza con la aplicación de la Ley. Pasa desde el territarias 37 conjunto de los recicladores hacia generar una rivalidad entre recicladores formales e informales

\section{3 ¿Hacia el fin de la recuperación informal de residuos?}

La Ley del Reciclador y los modelos implementados por los distritos no toman en cuenta los límites de cantidad de residuos reciclables. Es decir, hay demasiado recicladores para que la cantidad de residuos reciclables generados en los distritos pueda asegurar a todos ingresos dignos. A eso se 
añade el crecimiento constante del número de recicladores informales. Aunque una aplicación ideal e ilusoria de la recolección selectiva eliminaría la disponibilidad de residuos reciclables en las bolsas de desechos y por el mismo, impediría el reciclaje informal. Esto sigue siendo una ilusión porque incluso en los países con una recolección selectiva establecida no se eliminó las practicas informales (Duclos, 2015).

Según los cálculos de la ONG Alternativa cada reciclador debe tener trescientas viviendas en su zona de recojo selectivo, para llegar a $900^{.00}$ soles mensuales mientras que el sueldo mínimo alcanza los $850^{.00}$ soles en 2016. Esta meta parece difícil de alcanzar para que todos los recicladores de Lima vivan adecuadamente. Por ejemplo, en Comas, considerando el 100\% de las viviendas, la capacidad de formalización seria de setenta recicladores, mientras que hay 1780 recicladores en total (Ciudad Saludable, 2010). Actualmente son diecisiete recicladores que aseguran la recolección selectiva y venta de residuos por un promedio de $606^{.50}$ soles al mes. Para permitir a todos vivir de este trabajo y poner fin a los conflictos de apropiación de residuos, las municipalidades podrían reflexionar en gratificar a los recicladores, no por la venta de residuos, sino por el servicio de limpieza.

Las prácticas ilegales de los empleados de empresas prestadoras del servicio de recolección de desechos, constituyen una fuente de competencia desleal que no desapareció con la aplicación de la Ley del 2009. Estos empleados recuperan los residuos reciclables durante el recojo de las bolsas de desechos (ver figura 6) lo cual está prohibido, pero sancionar a estas empresas es difícil porque son prácticas de sus empleados y frecuentemente faltan pruebas. Regularizar las actividades de los centros de acopio y formalizarlos, puede permitir un control del origen de los residuos que compren y así impedir que estos residuos recuperados de forma ilegal encuentren un comprador. El modelo implementado en Comas trabaja con los centros de acopio, pero no controla el origen de residuos comprados.

\section{Conclusión}

Desde la Ley del Reciclador, las políticas públicas peruanas de manejo de residuos sólidos se posicionan en favor de

Figura 6. Empleados del camión de recolección de residuos y recuperación informal

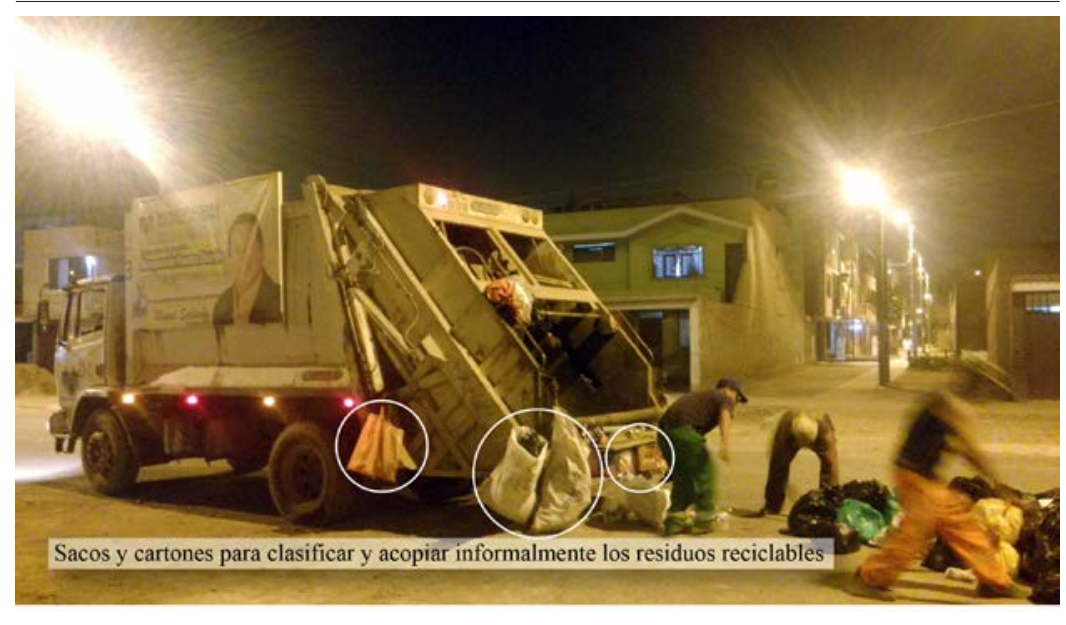

Fuente: Elaboración propia (2015). 
un reciclaje inclusivo, mediante la integración de los recicladores. Hoy en día, las políticas de represión se reemplazan poco a poco por políticas de formalización e integración de una parte de los actores informales de la cadena de valorización de los residuos reciclables. Si la Ley promueve la integración única de los recicladores, los modelos distritales de implementación de la Ley se muestran más innovadores integrando otros actores. Superando así una "descripción truncada de la cadena de recuperación y de reciclaje" que opera "una focalización exclusiva sobre los recicladores (Cavé, 2013, p. 88).

Este nuevo interés institucional para el reciclaje hubiera podido reavivar la competencia entre el servicio público de gestión y la lógica mercantil de reciclaje. Como se preguntaron Bertolini \& Nunesmaia (2002, p. 91): "la implementación y el desarrollo del recojo selectivo municipal [...] llevan a considerar su actividad tradicional de criba de los residuos como un forma de competencia". En vez de eso, la Ley reparte los papeles entre municipalidad y recicladores y el Ministerio del Ambiente promueve un incentivo para integrar a los reciclador, de tal forma que no se crea competencia.

La competencia de apropiación de "residuos reciclables" se desplaza desde el conjunto de los recicladores hacia generar una rivalidad entre recicladores formales e informales. Los formales tienen condiciones de trabajo mejoradas, tienen su zo-

\section{tersitarias 37} 78 resultado es la eliminación de competencia entre formales, pero sigue la competencia con los informales. Un mayor control de la cadena de reciclaje, fortalecido con innovaciones socio-institucionales, permitiría disminuir las oportunidades comerciales para los residuos de fuentes informales. $\mathrm{La}$ formalización permite también a los recicladores de beneficiarse del capital colectivo, en tanto los informales sufren de una marginalización acentuada. Estos últimos están discriminados por la municipalidad, los vecinos y por los mismos recicladores formales.

En la metrópoli de Lima-Callao, existen modelos de integración de recicladores suficientemente variados para poder encontrar políticas en favor de la estabilización del conflicto de apropiación del recurso "residuos reciclables". Los tres modelos estudiados en este artículo implementan innovaciones tecnológicas, sociales e institucionales (Bernal, 2015; Delpeuch, 2017; Paulré, 2017). Poco a poco estos modelos se orientan hacia un modelo común de innovación socio-institucional, incluyendo numerosos actores de la cadena de reciclaje el cual merecería estar estudiado más en profundidad para entender sus consecuencias sobre el conflicto.

\section{Referencias}

Barles, S. (2005). L'invention des déchets urbains, France: 1790-1970. París: Ed. Champ Vallon.

Bernal, M. E. (diciembre, 2015). Innovación social en gobierno. Conferencia magistral 
presentada en el Primer Encuentro Latinoamericano de Innovación Social para el Sector Público: nuevas perspectivas para superar la pobreza, Universidad de los Andes, Bogotá. Recuperado de http://vimeo.com/154602170

Bertolini, G. \& Brakez, M. (2008). Gestion des déchets, innovations et territoires. Retours d'expériences et recherche contextuelle. Marché et Organisations, (7), 151-182. Doi: 10.3917/ maorg.007.0092

Bertolini, G., Foully, B. \& Morvan, B. (1999). Le tri des ordures ménagères dans les pays en développement: Etude de cas au Brésil. Sciences et Techniques, (14), 30-38.

Bertolini, G. \& Nunesmaia, M. (2002). Pour une gestion des ordures ménagères socialement intégrée. Concept et étude de cas: Brésil et France. Géographie et cultures, (43), 87-105.

Cavé, J. (2013). La gestion disputée d'un mal public impur: économie politique des ordures. (Tesis doctoral). Escuela nacional de puentes y caminos, París, Francia.

Coffey, M. \& Coad, A. (2010). Collection of municipal solid waste in developing countries, United Nations Human Settlements Programme. Malta: UN-HABITAT.

Cointreau-Levine, S. (1982). Environmental management of urban solid wastes in developing countries: a project guide. Washington, DC: World Bank.

Gaudio, R. (2004). L'institutionnalisation de l'informel: regards sur la coopération et les stratégies de survie des chiffonniers dans trois villes brésiliennes. (Tesis doc- toral). Universidad de París I PanteónSorbona, París, Francia.

Delpeuch, T. (2017). L'innovation institutionnelle: une entreprise politique à base d'emprunts extérieurs. Quaderni, (91). Recuperado de http://quaderni. revues.org/1011

Duclos, M. (2015). Horizons d'égalité, le combat des biffins parisiens. (Tesis de doctorado). Universidad de París VII Denis Diderot, París, Francia.

Durand, M. (2010). Gestion des déchets et inégalités environnementales et écologiques à Lima. Entre vulnérabilité et durabilité. (Tesis de doctorado). Universidad de Rennes 2, Rennes, Francia.

Florin, B. (2010). Réforme de la gestion des déchets et reconfigurations des territoires professionnels des chiffonniers du Caire. Géocarrefour, 2(85), 109-118.

Furedy, C. (1992). Garbage: exploring nonconventional options in Asian cities. Environment and Urbanization, 4(2), 42-61.

Gerold, A. (2009). Integrating the informal sector in solid waste management systems. Basic aspects and experiences. Fráncfort: GTZ.

GIZ. (2010). Economic aspects of the informal sector in solid waste. Eschborn: GTZ.

GTZ. (2010). The waste experts: enabling conditions for informal sector integration in solid waste management. Lessons learned from Brazil, Egypt and India. Eschborn: GTZ.

Gunsilius, E., Chaturvedi, B. \& Scheinberg, A. (2011). The economics of the infor- territarios 37

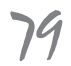


mal sector in solid waste management. Fráncfort: GIZ.

Gupta, S. K. (2012). Intégrer le secteur informel pour une meilleure gestion des déchets. Secteur Privéet Développement, (15), 12-15.

Madueño, D. (2012). El proceso de formalización de los recicladores y la reproducción de las condiciones de desigualdad en la microempresa Fuerza Emprendedora Lima Norte (FELN). Lima.

Medina, M. (enero, 2005). Waste picker cooperatives in developing countries. Ponencia presentada en la Conferencia de organizaciones con membresía para los pobres, WIEGO, Cornell \& SEWA, Ahmedabad.

Moreno-Sainz, M. (2007). Les récupérateurs de déchets à Buenos Aires: de l'exclusion à l'intégration sociale? $A u$ trepart, (43), 11-55.

Nas, P. J. M. \& Jaffe, R. (2004). Informal waste management: shifting the focus from problem to potential. Environment, Development and Sustainability, (6), 337-353.

ONG Ciudad Saludable. (2010). Por la ruta del reciclaje en el Perú. Estudio socioeconómico de la cadena del reciclaje. [Presentación en PDF]. Recuperado de http://sial.segat.gob.pe/documentos/presentacion-ruta-reciclaje-peruestudio-socioeconomico-cadenaLima

Paulré, P. (2016). L'innovation dans les sociétés contemporaines. Mises en pers- pective. Quaderni, (91). Recuperado de http://quaderni.revues.org/1006 República del Perú, Congreso de la República. Ley General de Residuos Sólidos (21 de julio de 2000).

República del Perú, Congreso de la República. Ley Que Regula La Actividad De Los Recicladores y Su Reglamentación (7 de octubre de 2009).

Scheinberg, A. \& Anschütz, J. (2006). Slim pickin's: supporting waste pickers in the ecological modernisation of urban waste management systems. International Journal of Technology Management and Sustainable Development, 5(3), 257270.

Scheinberg, A., Spies, S., Simpson, M. \& Mol, A. (2011). Assessing urban recycling in low- and middle-income countries: building on modernized mixtures. Habitat International, 35(2), 188-198.

un-Habitat. (2010). Solid waste management in the world's cities. Londres: United Nations Human Settlements Programme (UN-HABITAT).

Wilson, D., Araba, A., Chinwah, K. \& Cheeseman, C. (2009). Building recycling rates through the informal sector. Waste Management, 29(2), 629-635.

Wilson, D., Velis, C. \& Cheeseman, C. (2006). Role of informal sector recycling in waste management in developing countries. Habitat International, 30(4), 797-808. 